\title{
Prolonged myocardial stunning after thrombolysis: can left ventricular function be assessed definitely at hospital discharge?
}

\author{
M. Pfisterer, M. Zuber, R. Wenzel and F. Burkart \\ Division of Cardiology, University Hospital, Basel, Switzerland
}

KEY WORDS: Myocardial infarction, thrombolysis, myocardial stunning, LV function.

To assess whether myocardial dysfunction after acute reperfusion ('stunning') may show delayed recovery, 33 patients of the European Cooperative Study ( $r$ PA vs placebo) had radionuclide angiocardiography on day 9 and after 3-6 months. Sixteen patients (13 inferior, three anterior infarcts) had a normal left ventricular ejection fraction ( $L V E F)$ which remained unchanged (55.4 vs $53.9 \%$ ). In contrast, LVEF of 17 patients (10 inferior, seven anterior infarcts) with depressed values on day 9 improved during follow-up from 38.8 to $45.2 \%$. $(\mathrm{P}<0.01)$. Improvement was only observed in patients with early reperfusion defined a priori as peak creatine kinase value $\leqslant 15 \mathrm{~h}$ of pain onset (from 40.9 to $49.3 \%$; $\mathrm{P}<0.05$ ) in contrast to patients without reperfusion (from 34.0 to $35.2 \% ; n s$ ).'Accordingly, LVEF increased in patients with open infarct-related arteries at hospital discharge $(n=8 ; \mathrm{P}=0.053)$ but not with persistent occlusion $(n=7$; $\mathrm{P}=0 \cdot 11)$. Thus, a depressed LVEF observed 9 days after reperfusion may show delayed recovery due to prolonged stunning. Therefore, after thrombolysis, left ventricular function may not be evaluated definitively at hospital discharge; results of such studies should be interpreted with caution.

\section{Introduction}

Most large prospective studies of thrombolysis in acute myoardial infarction have shown a significant reduction in infarct size and improvement in survival vs standard treatment ${ }^{(1-6)}$, however, left ventricular (LV) function has been improved only marginally by this treatment ${ }^{[-9-9]}$. One reason for this apparent disparity of treatment effects may be slow recovery of post-ischaemic LV dysfunction. In clinical studies, LV function was usually assessed within the first few days after the acute infarct, before hospital discharge; however, experimental studies indicated that depending on the duration of the acute occlusion, full recovery of $L V$ function may take several weeks ${ }^{[10,11]}$. Since left ventricular ejection fraction (LVEF) remains fairly constant in patients after myocardial infarction without thrombolysis ${ }^{[12]}$, the aim of this study was to determine whether there would be an improvement in LVEF after hospital discharge in patients with early reperfusion, compared with those without reperfusion.

\section{Methods}

Since this study represents a substudy of the multicentre European Cooperative Study comparing the effects of recombinant tissue-type plasminogen activator (rtPA) vs placebo on LV function, the methods were identical to those reported earlier ${ }^{(6)}$. In short, patients below 71 years of age with acute chest pain lasting more than $30 \mathrm{~min}$ and Submitted for publication on 4 Janusry 1990 , and in revised form 20 April
1990 .

This report deals with a substudy of the Multicenter European Cooperative rTPA vs Placebo Study.

Adtress for correspondence M. Pfisterer M.D., F.E.S.C., Division of Cardiology, Department of Internal Medicine. University Hospital, $\mathrm{CH}-4031$ Basel, Switzertand. significant ST-elevation in more than one lead who could be treated within $5 \mathrm{~h}$ of pain onset were randomized to $100 \mathrm{mg}$ of rtPA or placebo, each combined with heparin and aspirin. Coronary and LV angiograms were only performed before hospital discharge, i.e. in our hospital on the 10th day after the acute event.

In addition to the general protocol, our patients underwent creatine kinase (CK) determinations every $4 \mathrm{~h}$ during the initial $24 \mathrm{~h}$ to detect early reperfusion, defined a priori for this study as time to peak CK of $\leqslant 15 \mathrm{~h}$; in addition radionuclide angiocardiograms were performed at rest 1 day prior to the contrast ventriculogram and 3 months later, after withdrawal of all cardiac medication for at least $24 \mathrm{~h}$. The $317 \mathrm{CK}$ values determined at our hospital as well as in the central laboratory of the European Cooperative Study in Maastricht $t^{[6]}$ showed excellent agreement: $y=-7 \cdot 1+2 \cdot 9 \mathrm{x}, \mathrm{r}=0.92, P<0 \cdot 0001$. LVEF determinations by our radionuclide technique and by the centrally analysed contrast ventriculograms showed also a significant correlation $(y=29 \cdot 3+0.5 x$, $\mathrm{r}=0.7, P<0.0001$ ), despite the fact that they were measured on different days and with different laboratory conditions. We have previously shown that the radionuclide LVEF values are valid and reproducible with a variability of 2 standard deviations $(95 \%)$ of $<5 \mathrm{EF} \%^{[13,14]}$.

\section{PATIENTS}

Included in this study were all 33 patients from our hospital, participating in the European Cooperative Study, who survived the acute event and follow-up and who had both early and follow-up radionuclide studies. There were 27 men and six women, with a mean age of 53.9 years (27-70 years). Ten patients had an anterior and 23 an inferior infarct, 18 had received rIPA and 15 
Table I Patients

\begin{tabular}{lcc}
\hline LVEF day 9 & $250 \%$ & $<50 \%$ \\
\hline $\mathrm{n}$ & 16 & 17 \\
mean age (years) & $53 \cdot 4$ & $54 \cdot 4$ \\
sex (male/female) & $14 / 2$ & $13 / 4$ \\
inferior/anterior infarct (n) & $13 / 3$ & $10 / 7$ \\
$1-/ 2-/ 3$-vessel disease (n) & $9 / 6 / 1$ & $11 / 4 / 1$ \\
rtPA/placebo (n) & $6 / 10$ & $12 / 5$ \\
PTCA/CABG (n) & 8 & 7 \\
\hline
\end{tabular}

LVEF = left ventricular ejection fraction, $\mathrm{rtPA}=$ recombinant tissue plasminogen activator, PTCA = percutaneous transluminal angioplasty, $\mathrm{CABG}=$ coronary artery bypass grafting.

placebo. Coronary angiography after 10 days showed one-vessel disease in 20, two-vessel disease in 10 and threevessel disease in two patients. Between early and followup studies, 15 patients had PTCA or CABG surgery. Patients were divided into two groups according to their initial radionuclide LVEF: 16 patients had a normal LVEF $\geq 50 \%$, as defined previously ${ }^{(15)}$; in this group no significant change was expected with time; 17 patients had an abnormal value of $<50 \%$ (Table 1). There were no significant differences between the two groups, although more patients with a depressed LVEF had received rtPA.

\section{Statistics}

All values are given as mean \pm 1 SEM. Groups were compared by Student's $t$-test for unpaired samples or the Chi square test, where appropriate, and values within one group were compared by Student's $t$-test for paired samples. $P$ values $<0.05$ were considered statistically significant, $<0 \cdot 10$ as of borderline significance and $>0 \cdot 10$ as non-significant.

\section{Results}

Changes in LV function between early and follow-up studies for patients with initially normal and abnormal LVEF values are shown in Fig. 1 . In patients with an LVEF of $\geq 50 \%$, values remained fairly constant over time, whereas they increased significantly in patients with a depressed value on day 9 . This increase was markedly higher than the spontaneous variability of this measurement with time $\mathrm{e}^{[14]}$.

In order to define factors responsible for this improvement in LVEF over time, patients with an initial value of $<50 \%$ were subdivided by time to peak CK (as a marker of early reperfusion) and drug treatment given (Fig. 2). There was a significant improvement only in patients with enzymatic signs of early reperfusion. Similarly, only patients who received rtPA showed a signficant late improvement of LVEF (from $37 \cdot 8+3 \cdot 2$ to $46 \cdot 5+4 \cdot 6 \%$, $P<0.01$; only one patient in each subgroup of Fig. 2 had to be exchanged).

When patients were subdivided by vessel patency according to the 10 day coronary angiogram, improvement of LVEF over time was only of borderline significance for eight patients with an open infarct-related artery (from $38.9 \pm 4.5$ to $44 \cdot 1 \pm 5.5 \% ; P=0.053$ ). There was no significant change for seven patients with subtotal/total occlusions before hospital discharge $(P=0 \cdot 11)$. LVEF tended to improve over time in both anterior and inferior infarcts, but the changes were not significant if analysed as two separate sub-groups.

\section{Discussion}

This small substudy of the European Cooperative Study, comparing the effects of rtPA and placebo on LV function, makes an important observation: the possibility of delayed recovery of LV function even after hospital discharge. This is not surprising in view of experimental evidence that reperfusion after $\leqslant 2$ h of coronary occulsion in dogs resulted in salvage of jeopardized myocardium with gradual improvement of function of salvaged tissue requiring 3 weeks or more ${ }^{[10]}$. Other studies suggested there may be even later but little recovery of function with occlusion of $3 \mathrm{~h}$ followed by reperfusion ${ }^{[11]}$. Investigations of the ultrastructure of this so-called 'stunned' myocardium ${ }^{[16]}$ indicated that reperfused, salvaged myocardium not only has functional and biochemical but also ultrastructural abnormalities and that the latter may persist even after there has been recovery of high energy phosphate stores and of function ${ }^{[10]}$. Similar observations of prolonged stunning and delayed recovery have been reported after emergency PTCA in cardiogenic shock patients ${ }^{[17]}$ and, most recently, after thrombolysis and documented reperfusion ${ }^{[18]}$, similarly to the present results. The latter contrast ventriculographic study also looked at regional function and showed that late improvement of global function was due to an increased motion of the infarct region ${ }^{[19]}$. Similarly to the present observations, improvement was mainly seen in large infarcts, i.e. in patients with a depressed LVEF and not in those with a normal function shortly after the acute event. Those two papers ${ }^{[18.19]}$, however, either described survival in relation to LV function or regional function but did not stress the clinical relevance of late recovery of $\mathrm{LV}$ function.

For this study, time to peak CK was defined a priori as a marker of early reperfusion since all other clinical parameters of reperfusion are even less reliable ${ }^{[20]}$. Unfortunately, no acute angiograms were performed as in the study by Schmidt $e t$ al..$^{[18]}$ where, again, late recovery of LV function was only found in patients with documented reperfusion. The 10 day angiogram in the present study also showed a difference in the extent of late recovery between patients with open vs those with subtotally or totally occluded infarct-related arteries. However, these angiographic findings reflect a 10-day vessel status and not early reperfusion since in the meantime spontaneous late (after hours or days) reperfusion and also silent reocclusion might have occurred in some patients, as observed in the European Cooperative Study ${ }^{6}$. Late recovery of function was mainly seen in patients treated with rtPA, which has been shown to increase early reperfusion significantly in comparison with placebo ${ }^{[22-24]}$. Finally, revascularization procedures were performed overall in similar percentages in patients with $(10 / 20)$ 

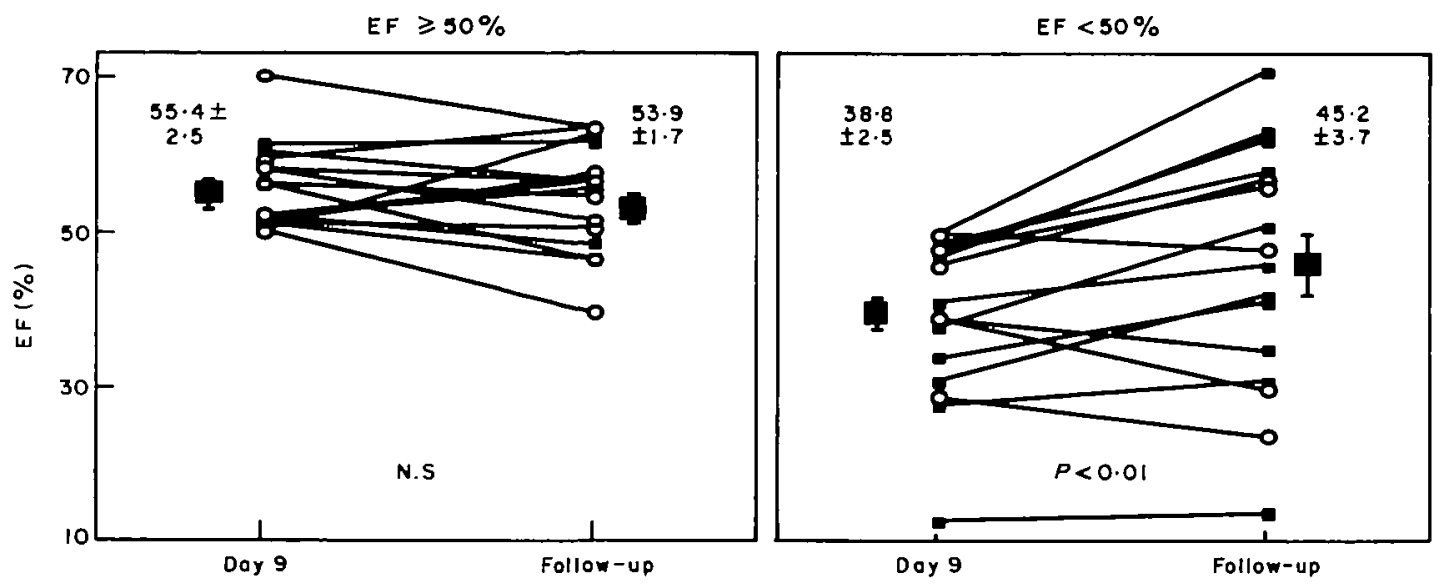

Figure $l$ Change in left ventricular ejection fraction (LVEF) over time. Note the significant improvement in LVEF in patients with an initial $L V E F<50 \%$ in contrast to no change in patients with a value of $\geq 50 \% . n=33$. $\square$ rtPA, O-O placebo.


Figure 2 Effect of early reperfusion assessed by time to peak maximal creatine kinase (CKmax) $\leqslant 15 \mathrm{~h}$ on the change of LVEF over tıme. Note the significant improvement in patients with signs of reperfusion vs no change in patients without reperfusion. $\mathrm{n}=17$ with intial EF $<50 \%$, $-\mathrm{rPA}, \mathrm{O}-\mathrm{O}$ placebo.

and without $(4 / 13 ; \mathrm{ns})$ signs of early reperfusion and have previously been shown not to change resting LVEF significantly ${ }^{[21]}$.

Although the sample size of this substudy may be too small to allow definite conclusions, the observations are in accordance with those of Schmidt $e t$ al.$^{[18]}$ as well as with experimental evidence of delayed functional recovery over weeks; they seem to imply that after acute myocardial infarction and thrombolysis $\mathrm{LV}$ function may not be definitely evaluated at hospital discharge. Studies analysing LV function within the first few days after acute myocardial infarction and thrombolysis should therefore be interpreted with caution. Thus, prolonged stunning might be one reason for the disparity between the effects of thrombolysis on infarct size and survival vs the lack of improvement in $\mathrm{LV}$ function reported in the literature.

\section{References}

[1] Gruppo Italiano per lo studio della streptochinasi nell'infarto miocardio (GISSI): Effectiveness of intravenous thrombolytic treatment in acute myocardial infarction. Lancet 1986; i: 397-401.

[2] The ISAM Study Group. A prospective trial of intravenous streptokinase in acute myocardial infarction (ISAM): Mortality, morbidity and infarct size at 21 days. N Engl J Med 1986; 314 : $1465-72$.

[3] AIMS Trial Study Group. Effect of intravenous APSAC on mortality after acute myocardial infarction: Preliminary report of a placebo-controlled clinical trial. Lancet 1988; i: 545-9.

[4] ISIS-2 (Second International Study of Infarct Survival) Collaborative Group. Randomised trial of intravenous streptokinase, oral aspirin, both or neither among 17187 cases of suspected acute myocardial infarction: ISIS-2. Lancet 1988; ii: $349-60$.

[5] Wilcox RG, Von Der Liffe G, Olsson CG, Jensen G, Skene AM, Hampton JR For The Asset Study Group. Trial of tissue plasminogen activator for mortality reduction in acute myocardial infarction. Anglo-Scandinavian Study of Early Thrombolysis (ASSET). Lancet 1988; ii: 525-30.

16] Van De Werf F, Arnold AER and the European Cooperative Study Group for Recombinant Tissue-type Plasminogen Activator (nPA). Effect of intra venous tissue plasminogen activator on infarct size, left ventricular function and survival in patients with acute myocardial infarction. Br Med J 1988; 297 : 1374-9.

[7] Ritchie JL, Cerqueira M, Maynard C, Davis K, Kennedy W Ventricular function and infarction size: The Western 
Washington intravenous streptokinase in myocardial infarction trial. J Am Coll Cardiol 1988; 11: 689-97.

[8] White HD, Norris RM, Brown MA et al. Effect of intravenous streptokinase on left ventricular function and early survival after acute myocardial infarction. N Engl J Med 1987; 317: $850-5$.

[9] National Heart Foundation of Australia Coronary Thrombolysis Group. Coronary thrombolysis and myocardial salvage by tissue plasminogen activator given up to 4 hours after onset of myocardial infarction. Lancet 1988; i: 203-7.

[10] Ellis SG, Henschke CI, Sandor T, Wynne J, Braunwald E Kloner RA. Time course of functional and biochemical recovery of myocardium salvaged by reperfusion. J Am Coll Cardiol 1983; 1: 1047-55.

[11] Lavalle M, Vatner SF. Recovery of regional myocardial function in border and severely ischemic zones following coronary artery reperfusion in conscious dogs. Circulation 1982; 66 (Suppl 2): 262.

[12] Borer JS, Rosing DR, Miller RH et al. Natural history of left ventricular function during 1 year after acute myocardial infarction: comparison with clinical, electro-cardiographic and biochemical determination. Am J Cardıol 1980; 46: 1-12.

[13] Pfisterer ME, Ricci DR, Schuler D et al. Validity of leftventricular ejection fractions measured at rest and peak exercise by equilibrium radıonuclide angiography using short acquisition times. J Nucl Med 1979; 20* 484-90.

[14] Pfisterer ME, Battler A, Swanson SM el al. Reproducibility of ejection fraction determinations by equilibrium radionuclide angiography in response to supine bicycle exercise. J Nucl Med $1979 ; 20.491-4$.

[15] Pfisterer M, Battler A, Zaret BL. Range of normal values for left and night ventricular ejection fraction of rest and durnng exercise assessed by radionuclide angiocardıgraphy. Eur Heart J 1985; 6: 647-55.

[16] Braunwald E, Kloner RA. The stunned myocardium: prolonged, postischemic ventricular dysfunction. Circulation 1982; 66: 1146-9.
[17] Zuber M, Pfisterer M, Kiowski W, Schmitt HE, Ritz R, Burkart F. Emergency coronary angioplasty in acute myocardial infarc. tion with contraindications to thrombolytic therapy: salvage of myocardium by early intervention. Schweiz Rundschau Med 1989; 7: 863-7.

[18] Schmidt WG, Sheehan FH, v. Essen R, Uebis R, Effert S. Evolution of left ventricular function after intracoronary thrombolysis for acute myocardial infarction. Am J Cardiol 1989; 63: 497-502.

[19] Sheehan FH, Doerr R, Schmidt WG et al. Early recovery of left ventricular function after thrombolytic therapy for acute myocardual infarction: An important determinant of survival. J Am Coll Cardiol; 12: 289-300.

[20] Blanke $H$, von Hardenberg D, Cohen $M$ et al. Pattern of creatine kinase release during acute myocardial infarction after non-surgical reperfusion: comparison with conventional treatment and correlation with infarct size. J Am Coll Cardiol 1984; 3: $675-80$.

[21] Hammermeister KE, Kennedy JW, Hamilton GW et al. Aortocoronary saphenous vern bypass - failure of successful grafting to improve resting left ventricular function in chronic angina. N Engl J Med 1974; 290: 186.

[22] Chesebro JH, Knatterud G, Roberts R et al. Thrombolysis in myocardial infarction (TIMI) trial, Phase I: A comparison between intravenous tissue plasminogen activator and intravenous streptokinase. Circulation 1987; 76: 142-54.

[23] Verstraete M, Bory M, Collen D. Randomised trial of intravenous recombinant tissue-type plasminogen activator versus intravenous streptokinase in acute myocardial infarction. Lancet 1985; ii: 842-7.

[24] Topol EJ, Califf RM, George BS et al. and the Thrombolysis and Angioplasty in Myocardial Infarction (TAMI) Study Group. A multicenter randomized trial of intravenous recombinant tissue plasminogen activa tor and immediate angioplasty in acute myocardial infarction. $N$ Engl $J$ Med $1987 ; 317 \cdot 581-8$. 